\title{
GRANULAR OPEN FILTERS ON A HORIZONTAL BED UNDER WAVE AND CURRENT LOADING
}

\author{
Guido Wolters ${ }^{1}$ and Marcel R.A. van Gent ${ }^{2}$
}

\begin{abstract}
Rubble mound coastal structures typically contain granular filters in one or more layers. These filters are normally geometrically tight (to prevent material washout), often difficult to realize in the field, and expensive. An alternative is a geometrically open filter (i.e. a large ratio of the size of toplayer material and underlayer material), designed in such a way that it fulfills its filter functions with only minimal base material loss or settlement. Potential applications of open filters include bed protections and toe \& slope configurations of coastal structures. Proper guidelines on the design of open filters under wave and current loading could lead to significant cost and material savings, and to a more practical application of filters in the field. The physical model tests conducted in this study focus on granular open filters on a horizontal sand bed under wave and combined wave \& current loading.
\end{abstract}

Keywords: rubble-mound breakwater; open filter; transport filter; waves; currents; physical model tests

\section{INTRODUCTION}

The majority of rubble mound coastal structures contains granular filters where a large rock grading is positioned on top of a smaller rock grading, often with one or more layers. These filters are normally geometrically tight filters (no material washout). Underneath the filter layers quarry material is present, or a combination of a geotextile with sand as core material.

Geometrically tight filters are often difficult to realize and expensive. In many instances a large number of filter layers and material volume is required. Furthermore, geometrically tight filters are often difficult to realise in the field because of quarry material limitations and when the structure is constructed underwater.

An alternative is a geometrically open filter (i.e. a large ratio of the size of toplayer material and underlayer material). In this case the filter is designed in such a way that the hydraulic loading is too low to initiate erosion of base material (or settlement) outside an acceptable range. Limited settlement is often permitted in the field. Potential applications of open filters include bed protections and toe \& slope configurations of coastal structures. The allowed settlement depends on the structure type. For breakwaters and revetments even small amounts of toe settlement can endanger the stability of the armour layer by loosening the bonds between interlocked armour units or placed block revetments. This could lead to the failure of the structure as a whole (see e.g. CIRIA, CUR, CETMEF 2007).

Geometrically open filters are either hydraulically closed filters (in which incipient motion of base material is not exceeded) or transport filters (in which transport of base material occurs). Transport filters can be subdivided into filters where transport of base material occurs only within the filter and filters where base material transport occurs also outside the filter.

Proper guidelines on the design of geometrically open filters that allow an acceptable and predictable loss of base material under wave and current loading, could lead to significant cost and material savings, and to a more practical application of filters in the field.

The presented work is an exploratory study for a more extended research effort on open filters. The physical model tests that are described here focus on granular open filters on a horizontal sand bed under wave and combined wave-current loading.

\section{PREVIOUS RESEARCH}

In the 1980s and 1990s a large number of tests have been performed by e.g. De Graauw et al (1983), Bakker et al (1994), Klein Breteler (1989), Klein Breteler et al (1992) to determine criteria for the initiation of motion in granular filters. This research has resulted in various formulae and design diagrams for interface stability of granular filters, which have been incorporated in CUR report 161 (1993). Furthermore, new criteria for interface stability have been introduced in CUR report 233 (2010), which are however not yet verified by experimental data.

\footnotetext{
${ }^{1}$ Deltares, P.O. Box 177, 2600 MH, Delft, The Netherlands, guido.wolters@deltares.nl

2 Deltares, P.O. Box 177, 2600 MH, Delft, The Netherlands, marcel.vangent@deltares.nl
} 
The above mentioned research studies have been conducted with a focus on steady flow and the initiation of base material transport through/within the filter. The studies do not specifically address base material transport itself or filter settling effects.

Very little knowledge is available about base material transport (and critical hydraulic gradients) in filters under cyclic (unsteady) loading. Reference is made to De Graauw et al (1983), who focussed on cyclic flow perpendicular to the sand-filter interface, Uelman (2006) and Ockeloen (2007), who studied a breakwater with an open filter but did not develop a criterion for the assessment of incipient motion under wave loading and Dixen et al (2008), who determined the onset of transport of sand underneath single sized armour blocks. Although these studies discuss various aspects of cyclic (wave) loading, they do not specifically address the problem of base material transport in filters.

To design open filters for applications under wave loading, and combined wave-current loading, more information is needed before the potential cost-savings of applying open filters can be scientifically justified. Therefore, the present study focusses on granular open filters on a sand bed under wave and combined wave \& current loading.

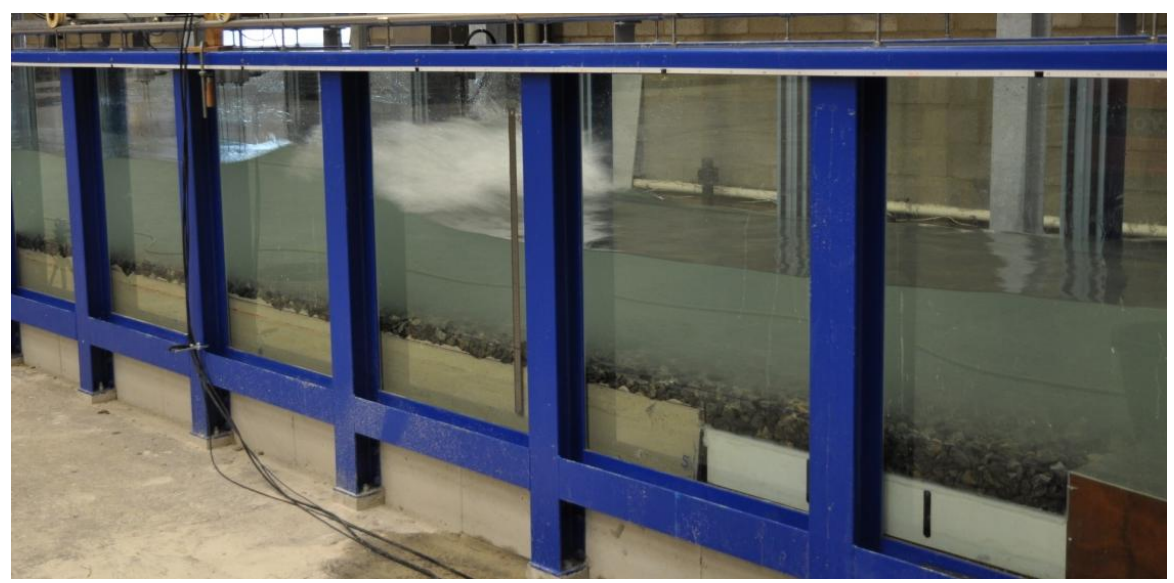

Figure 1. Wave flume: Breaking waves above open filter.

In the following section the criteria for the initiation of motion in granular filters (steady flow), as presented by De Graauw et al (1983), Klein Breteler (1989), Klein Breteler et al (1992) are discussed in more detail.

\section{Critical filter velocity \& critical hydraulic gradient}

In his study from 1989, Klein Breteler (1989) analyses a horizontal, steady flow through a granular filter on top of a sand bed. Sand transport measurements were conducted from which the critical filter velocity and critical gradient at the beginning of transport were determined. Based on the measurements Klein Breteler (1989) and Den Adel (1992) derived Equations 1 and 2 for the critical filter velocity, $u_{f, c r}$, for the initiation of base particle motion under steady flow:

$$
\begin{array}{ll}
u_{f, c r}=\left[\frac{n_{f}}{c}\left[\frac{D_{15, f}}{v_{w}}\right]^{m} \sqrt{\psi \cdot g \cdot \Delta \cdot D_{50, b}}\right]^{1 /(1-m)} & \text { for } 0,1 \mathrm{~mm}<D_{50, b}<1 \mathrm{~mm} \\
u_{f, c r}=\frac{n_{f}}{0.22} \sqrt{\left(\psi \cdot g \cdot \Delta \cdot D_{50, b}\right)} & \text { for } D_{50, b}>0,7 \mathrm{~mm}
\end{array}
$$

with

$u_{f, c r}=$ critical filter velocity, where $u_{\mathrm{f}}$ is the averaged velocity over the cross-section of the filter $(\mathrm{m} / \mathrm{s})$

$g \quad=$ acceleration due to gravity $\left(\mathrm{m} / \mathrm{s}^{2}\right)$

$\Delta \quad=\rho_{s} / \rho_{w}-1=$ relative submerged density of base material (-)

$\rho_{s}=$ density of base material, $\rho_{w}=$ density of water $\left(\mathrm{kg} / \mathrm{m}^{3}\right)$

$\Psi=$ Shields parameter for base material (-).

$m, c=$ constants, dependent on $D_{50, b}(-)$; see Table 1.

$v_{w}=$ kinematic viscosity of water $\left(\mathrm{m}^{2} / \mathrm{s}\right)$ 


\begin{tabular}{|lll|}
\hline \multicolumn{2}{|c|}{ Table 1. Parameters according to Klein Breteler et al (1992) } \\
\hline$D_{\mathrm{b} 50}(\mathrm{~mm})$ & $c(-)$ & $\mathrm{m}(-)$ \\
\hline 0,1 & 1,18 & 0,25 \\
0,15 & 0,78 & 0,20 \\
0,2 & 0,71 & 0,18 \\
0,3 & 0,56 & 0,15 \\
0,4 & 0,45 & 0,11 \\
0,5 & 0,35 & 0,07 \\
0,6 & 0,29 & 0,04 \\
0,7 & 0,22 & 0 \\
0,8 & 0,22 & 0 \\
1,0 & 0,22 & 0 \\
\hline
\end{tabular}

For the critical hydraulic gradient (parallel to the filter-bed interface, as measured in this study) the following empirical relationship can be used, developed for initiation of transport under steady flow (De Graauw, 1983), see Equation 3:

$$
i_{c r}=\left[\frac{0.06}{n_{f}^{3} D_{15, f}^{4 / 3}}+\frac{n_{f}^{5 / 3} D_{15, f}^{1 / 3}}{1000 D_{50, b}^{5 / 3}}\right] u_{* c r}^{2}
$$

where (for sand as base material, Equation 4):

$$
u_{*_{c r}}=1.3 D_{50, b}^{0.57}+8.3 \cdot 10^{-8} D_{50, b}^{-1.2}
$$

with

$D_{15, f}=$ diameter of filter material exceeded by $85 \%$ (mass) (m)

$D_{50, b}=$ diameter of bed material exceeded by $50 \%$ (mass) (m)

$i_{c r} \quad=$ critical hydraulic gradient, parallel to the filter-bed interface (-)

$u_{* r}=$ critical shear velocity of base material $(\mathrm{m} / \mathrm{s})$

$n_{f} \quad=$ porosity of filter material (-)

Please note that Equations 3 and 4 are dimension-dependent. Very similar results to Equation 3 are obtained if $i_{c r}$ is calculated using the Forchheimer equation (based on $u_{c r}$ ). Furthermore, experience (at prototype) has shown that the De Graauw criteria is relatively conservative. The Forchheimer equation could lead here to larger $i_{c r}$ values (and thus to smaller required filter layers). For more information on the Forchheimer relation as applied to granular filters, reference is made to CUR 161 (1993) and Van Gent (1995).

Based on the previously introduced formula for the critical filter velocity and the critical hydraulic gradient the following critical values can be calculated for $D_{f, 15}=20-30 \mathrm{~mm}$ (stationary current): $u_{f, c r} \approx$ $0.02-0.03 \mathrm{~m} / \mathrm{s}$ and $i_{c r} \approx 0.06-0.07$.

The current study indicates that (as Klein Breteler et al surmise in their 1992 study) the above described criteria for initiation of motion are also applicable to cyclic loading. Initiation of motion was observed for $i / i_{c r} \sim 1$. These initial tests are not described in this paper, since they did not result in any base material transport (see section on observations).

\section{Macroscopic transport model}

Based on the critical hydraulic gradient (respectively the critical filter velocity), as introduced in the previous section, Klein Breteler et al (1992) developed the following empirical transport formulae for macroscopic base material transport within filters (steady flow, homogeneous base material):

$$
T=\rho_{s} \cdot p_{1} \cdot\left(i / i_{c r}-1\right)^{1.25}
$$

or 


$$
T=\rho_{s} \cdot p_{2} \cdot\left(\left(u_{f} / u_{f, c r}\right)^{2}-1\right)^{1.5}
$$

where:

$T=$ transport rate in $(\mathrm{kg} / \mathrm{m} / \mathrm{s})$

$\rho_{s} \quad=$ density of transported material $\left(\mathrm{kg} / \mathrm{m}^{3}\right)$

$u_{f, c r}=$ critical filter velocity $(\mathrm{m} / \mathrm{s})$

$i_{c r}=$ critical hydraulic gradient, parallel to the filter-bed interface (-)

$p_{i} \quad=$ transport intensity $\left(\mathrm{m}^{3} / \mathrm{m} / \mathrm{s}\right)$

These formulae are based on the assumption of a turbulent flow, i.e. the hydraulic gradient is proportional to the square of the filter velocity. Equation 6 , based on $u_{f, c r}$, was derived from the classical formula of Meyer-Peter and Mueller for bedload transport in free surface flows.

The value of the transport intensity, $p_{i}$, was found to be independent of the diameter of the transported material and in the range of:

$$
p_{i}=0.6 \times 10^{-6}-9.0 \times 10^{-6} \mathrm{~m}^{2} / \mathrm{s} \text { with a best fit for } p_{i}=1.5 \times 10^{-6} \mathrm{~m}^{2} / \mathrm{s}
$$

\section{PHYSICAL MODEL TESTS}

Physical model tests were performed in a wave \& current flume (length $110 \mathrm{~m}$, width 1m, height $1.2 \mathrm{~m})$ at Deltares, Delft. The set-up of the model consisted of a submerged granular filter construction on a sand bed which was subjected to waves, currents and wave \& current loading, see Figure 2.

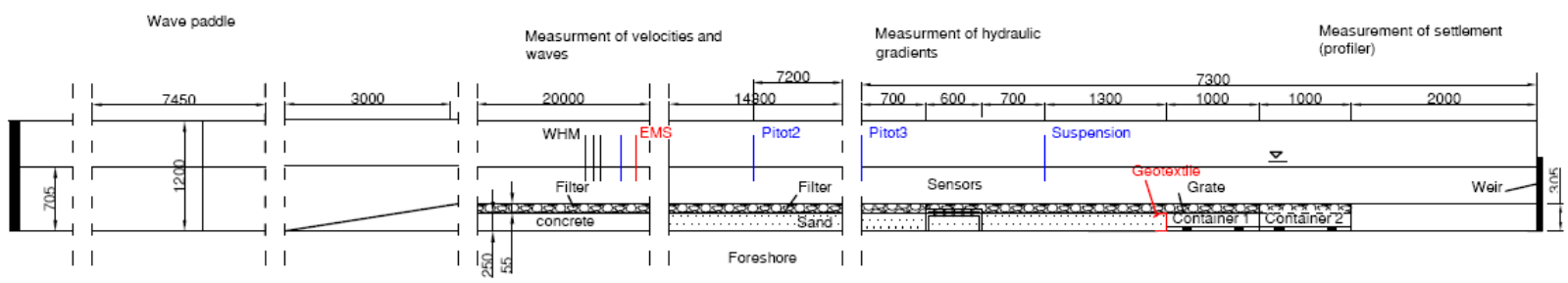

a) Set-up for current and combined wave \& current loading.

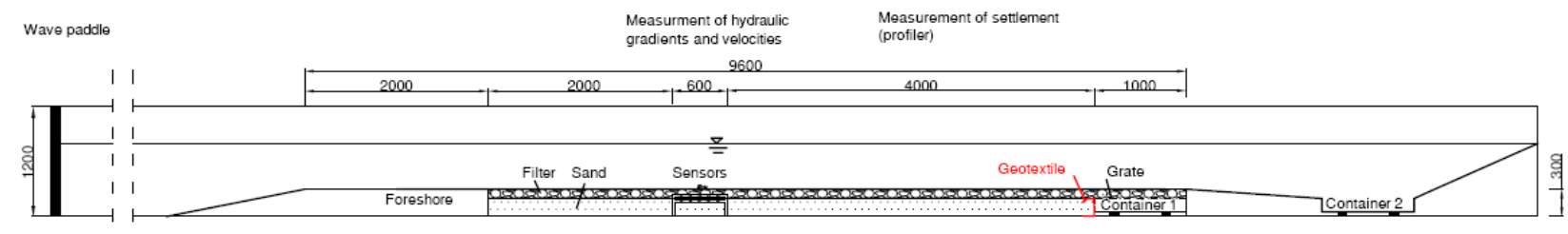

b) Set-up for wave loading (see Wolters et al, 2010).

Figure 2. Model set-up in the Scheldt Flume of Deltares, Delft.
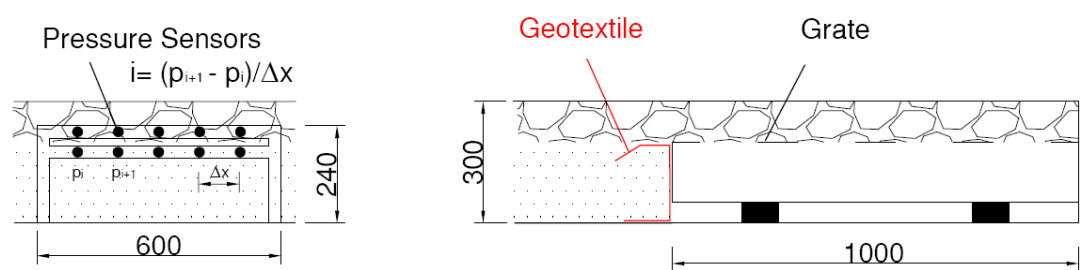

Figure 3. Pressure transducer frame at rock-sand interface ( 2 rows of 5 pressure sensors each, $25 \mathrm{~mm}$ above and below the filter-sand interface).

A concrete foreshore $\left(0.305 \mathrm{~m}\right.$ thick) was used in which a granular filter layer of $d_{f}=0.055 \mathrm{~m}$ or $0.1 \mathrm{~m}$ thickness $\left(D_{n 50, f}=20-30 \mathrm{~mm}, d_{f} / D_{\mathrm{n} 50, f}=1.8-3.3, M_{85, f} / M_{15, f}=3.4-4.6, \rho_{s, f}=2650-2700 \mathrm{~kg} / \mathrm{m}^{3}\right)$ and a sand layer of $d_{b}=0.25 \mathrm{~m}$ or $0.205 \mathrm{~m}$ thickness $\left(D_{50, b}=0.15-0.16 \mathrm{~mm}, D_{50, f} / D_{50, b}=150-220\right)$ were embedded. Tests were conducted for two filter thicknesses (plus a reference case without filter) and two filter stone sizes. The porosity of the filter material was estimated from the sieving curve to be $n=$ 0.44. The horizontal concrete-filter section (length $L=20 \mathrm{~m}$ ) in front of the measurement area allowed 
the turbulent flow conditions within the filter layer and the full water depth to become fully developed before any measurements were conducted. The transported sand was collected in two containers behind the filter section.

Measurements were performed of the incident waves, velocities above the filter bed, base material (sand) transport, filter settlement using a mechanical profiler, pressures and pressure gradients in filter and sand bottom (e.g. Figure 2 and 3). Also instrumentation was present to measure the water surface and the velocity profile. Ripple lengths, heights and sand movements along the seabed were also monitored. The hydraulic gradients $i$ and $i_{c r}$ have been directly measured at the sand-filter interface (parallel to interface). A wide grading of the filter material was chosen since these are the most realistic to be applied in open filters.

Waves up to $H_{s}=0.2 \mathrm{~m}$ (JONSWAP spectrum, second-order waves) were generated and horizontal depth-averaged current velocities up to $u_{m}=1.25 \mathrm{~m} / \mathrm{s}$. The base material (sand) and the water depth above the open filter $\left(h_{f}=0.4 \mathrm{~m}\right)$ were kept constant during all tests. Conditions in the filter bed were always in the turbulent regime (though fully turbulent conditions were not always achieved).

$K C_{f}$ numbers between $K C_{f}=\left(u_{2 \%} T_{m}\right) /\left(n_{f} d_{f}\right)=10-250$ (based on $u_{2 \%}=$ velocity directly above the filter exceeded by $2 \%$ of waves), and mobility numbers between $\theta_{\max }=u_{\max }{ }^{2} / g / \Delta / D_{50, b}=49-1388\left(\theta_{2 \%}\right.$ $=27$ - 794) were measured. The $K C_{f}$ number is here based on the filter thickness $d_{f}$ instead of the filter stone diameter $D_{n 50, f}$.

\begin{tabular}{|c|c|c|c|c|c|c|c|c|c|c|c|c|}
\hline \multirow[t]{2}{*}{ Test } & \multirow[t]{2}{*}{ Loading } & \multicolumn{3}{|c|}{ Test parameters } & \multicolumn{5}{|c|}{ Loading conditions } & \multicolumn{3}{|c|}{ Measured } \\
\hline & & $\begin{array}{l}D_{n 50, f} \\
(m m)\end{array}$ & $\begin{array}{c}d_{f} \\
(m)\end{array}$ & $\begin{array}{l}\mathrm{h}_{\mathrm{f}} \\
(\mathrm{m})\end{array}$ & $\begin{array}{c}\mathrm{H}_{\mathrm{s}} \\
(\mathrm{m})\end{array}$ & $\begin{array}{l}\mathrm{T}_{\mathrm{p}} \\
\text { (s) }\end{array}$ & $\begin{array}{l}\mathrm{s}_{\mathrm{op}} \\
(-)\end{array}$ & $u_{m}$ & $\begin{array}{l}\mathrm{t}_{\text {Tot }} \\
(\mathrm{hrs})\end{array}$ & $\begin{array}{c}\mathrm{u}_{2 \%} \\
(\mathrm{~m} / \mathrm{s})\end{array}$ & $\begin{array}{c}\mathrm{T} \\
(\mathrm{g} / \mathrm{m} / \mathrm{s})\end{array}$ & $\begin{array}{l}\mathrm{T}^{*} \\
(-)\end{array}$ \\
\hline T01 & current & 22 & 0,055 & 0,4 & - & 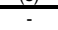 & $\frac{1}{-}$ & 1,25 & 8,48 & 1,00 & 0,062 & 0,0029 \\
\hline T02 & current + waves & 22 & 0,055 & 0,4 & 0,06 & 1,98 & 0,009 & 0,63 & 0,50 & 0,68 & - & $0,00<0$ \\
\hline T03 & current + waves & 22 & 0,055 & 0,4 & 0,11 & 2,51 & 0,011 & 0,13 & 6,00 & 0,35 & 0,008 & 0,0004 \\
\hline T04 & current + waves & 22 & 0,055 & 0,4 & 0,15 & 3,01 & 0,011 & 0,13 & 6,00 & 0,71 & 0,007 & 0,0003 \\
\hline T05 & current + waves & 22 & 0,055 & 0,4 & 0,12 & 2,99 & 0,008 & 0,63 & 6,00 & 1,03 & 0,031 & 0,0014 \\
\hline T06 & current + waves & 22 & 0,055 & 0,4 & 0,12 & 5,08 & 0,003 & 0,63 & 6,00 & 0,92 & 0,043 & 0,0020 \\
\hline T07 & current + waves & 22 & 0,055 & 0,4 & 0,14 & 5,69 & 0,003 & 0,63 & 6,00 & 1,14 & 0,063 & 0,0029 \\
\hline T08 & current & 22 & 0,055 & 0,4 & 0,79 & &, 000 & 1,06 & 6,00 & 1,02 & 0,052 & 0,0024 \\
\hline T09 & current + waves & 22 & 0,055 & 0,4 & 0,10 & 5,07 & 0,002 & 1,06 & 4,18 & 1,43 & 0,203 & 0,0094 \\
\hline T10 & current & 22 & 0,055 & 0,4 & - & - & - & 0,63 & 6,00 & 0,60 & 0,006 & 0,0003 \\
\hline $\mathrm{T} 11$ & current & 22 & 0,055 & 0,4 & - & - & - & 1,06 & 6,00 & 0,91 & - & - \\
\hline $\mathrm{T} 12$ & current + waves & 22 & 0,055 & 0,4 & 0,10 & 5,08 & 0,002 & 1,06 & 2,00 & 1,20 & 0,331 & 0,0153 \\
\hline \multicolumn{13}{|c|}{ Reference tests (without filter) } \\
\hline $\mathrm{T} 13$ & current & - & - & 0,455 & - & - & - & 0,55 & 0,50 & 0,65 & 12,265 & 0,5684 \\
\hline T14 & current + waves & - & - & 0,455 & 0,13 & 5,10 & 0,003 & 0,55 & 0,50 & 1,13 & 33,553 & 1,5550 \\
\hline \multicolumn{13}{|c|}{ Wave tests (Wolters et al. 2010) } \\
\hline T05 & waves & 30 & 0,1 & 0,4 & 0,10 & 2,09 & 0,015 & - & 6 & 0,26 & 0,102 & 0,0047 \\
\hline T06 & waves & 30 & 0,1 & 0,4 & 0,14 & 2,52 & 0,014 & - & 6 & 0,38 & 0,079 & 0,0037 \\
\hline T07 & waves & 30 & 0,1 & 0,4 & 0,17 & 5,41 & 0,004 & - & 2 & 0,88 & 0,161 & 0,0075 \\
\hline T08 & waves & 30 & 0,055 & 0,4 & 0,14 & 2,52 & 0,014 & - & 6 & 0,43 & 0,063 & 0,0029 \\
\hline T09 & waves & 30 & 0,055 & 0,4 & 0,14 & 1,80 & 0,027 & - & 6 & 0,32 & 0,063 & 0,0029 \\
\hline T10 & waves & 30 & 0,055 & 0,4 & 0,16 & 5,10 & 0,004 & - & 2 & 0,86 & 0,068 & 0,0031 \\
\hline $\mathrm{T} 11$ & waves & 20 & 0,055 & 0,4 & 0,14 & 2,52 & 0,014 & - & 6 & 0,41 & 0,035 & 0,0016 \\
\hline T12 & waves & 20 & 0,055 & 0,4 & 0,14 & 1,81 & 0,027 & - & 6 & 0,32 & 0,033 & 0,0015 \\
\hline T13 & waves & 20 & 0,055 & 0,4 & 0,16 & 5,10 & 0,004 & - & 2 & 0,88 & 0,040 & 0,0019 \\
\hline
\end{tabular}

The test programme is given in Table 2 . The test duration $\left(t_{T o t}\right)$ varied between tests, based on the observed base material transport (1000-12000 waves). Short duration tests (1000 waves) were employed for the reference case without filter layer, due to the large amounts of sand transported. The measured transported base material is given in Table 2 as $T(\mathrm{~g} / \mathrm{m} / \mathrm{s})$ and in dimensionless form $T^{*}(-)$ :

where:

$$
T^{*}=\frac{T / \rho_{s}}{\sqrt{\Delta g D_{50, b}^{3}}}
$$

$\Delta=$ relative buoyant density of base material $\left(\rho_{s} / \rho_{w}-1\right)$

\section{OBSERVATIONS}

Wave loading (see Wolters et al, 2010)

The tests were originally set-up to investigate bedload and suspended load transport separately. However, it became apparent during testing that these two regimes could not be separated, since significant base material transport could only be realized once the filter velocities were far above the critical velocity and once base material was also suspended in the water column. 
Measurable material transport was first observed for wave heights of $H_{s}=0.1 \mathrm{~m}$ and $u_{2 \%}=0.25 \mathrm{~m} / \mathrm{s}$ $\left(i_{2} \% / i_{c r}=2, u_{2} \% / u_{c r}=10-14\right)$. At this stage bed ripples beneath the filter layer became fully formed with heights of 10-20 mm and 70-170 mm length.

The observed base material transport for wave loading alone was very low $(T<0.16 \mathrm{~g} / \mathrm{s} / \mathrm{m})$ for all tested filter configurations, even for large near-bed velocities $\left(u_{2} \% / u_{c r}=10-38\right)$ and hydraulic gradients $\left(i_{2} \% / i_{c r}=2-3.7\right)$, see Figure 6. It was observed that while the hydraulic gradients (measured parallel to the filter-bed interface) were sufficiently high to produce initiation of motion around the rest position and some suspension of bed material, most of the bed material remained in its original vicinity.

The tests showed that the base material distribution (sieving curve) changed during transport. Whereas the original sand (current loading) had a median particle size of $D_{50, b}=152 \mu \mathrm{m}$, the particle size of the transported bedload material was $D_{50, b}=142 \mu \mathrm{m}$ and that of the suspended load $D_{50, b}=$ $104 \mu \mathrm{m}$. The heaviest sand particles were left behind during bedload transport and only the lighter particles were transported in suspended mode. It was observed that the finer sand particles were entrained into the water column (particles $<60 \mu \mathrm{m}$ ) very quickly, clouding the water. Most of this material was so fine that it remained suspended in the water column even days after testing.

\section{Current loading}

For low current velocities $\left(u_{2 \%}<0,6 \mathrm{~m} / \mathrm{s}\right)$ no base material transport was observed. Measurable material transport was observed at $u_{2} \%>1 \mathrm{~m} / \mathrm{s}\left(i_{2} \% / i_{c r}>2, u_{2} \% / u_{c r}>19\right)$. First particle clouds were seen moving through the filter, and initial scouring at some stone locations occurred.

Compared to the case of wave loading the velocity at (observed) transport initiation was somewhat larger $\left(u_{2} \% / u_{c r}=19\right.$ in place of $\left.u_{2 \%} / u_{c r}=10-14\right)$, although the hydraulic gradient was similar $\left(i_{2 \%} / i_{c r} \approx 2\right)$.

The observed base material transport for current loading was very low $(<0.06 \mathrm{~g} / \mathrm{s} / \mathrm{m})$ for all tested filter configurations, see Figure 5.

\section{Wave \& current loading}

\section{$U_{2 \%}<0.6 \mathrm{~m} / \mathrm{s} \quad\left(i_{2 \%} / i_{c r}<2.3\right)$}

First entrainment of small sand clouds into the filter was observed at $H_{s}=0.11 \mathrm{~m}$, but the observed base material transport was very low (just above the measurement threshold). At this low current velocity practically no difference in transport was found for waves between $H_{s}=0.11 \mathrm{~m}$ and $H_{s}=$ $0.15 \mathrm{~m}$ (maximum wave condition which could be reached for the investigated current loading, see below).

$U_{2 \%} \geq 0.6 \mathrm{~m} / \mathrm{s}\left(i_{2 \%} / i_{c r}>2.3\right)$

Regular entrainment of sand clouds into filter and water column was observed $\left(i_{2} \% i_{c r}=3.0-4.9\right.$, $\left.u_{2 \%} / u_{c r}=29-45\right)$. A steady increase of base material transport was found for increasing current velocities $\left(u_{2} \%=0.6-1.25 \mathrm{~m} / \mathrm{s}\right)$ and increasing wave periods $\left(K C_{f}\right.$ numbers $)$.

During the tests it was observed that with increasing current velocity, only a fraction of the generated wave height could be realized (sometimes $50 \%$ of generated $H_{s}$ ) in the flume. This is mainly caused by the typical interaction of waves and current (energy conservation: an increase in wave length by stronger currents is followed by a decrease in wave height). In Table 2 only the realized wave heights are given, which correspond to generated wave heights at the wave paddle of $H_{s}$ $\leq 0.2 \mathrm{~m}$.

\section{Erosion profiles}

The measured erosion and filter settlement were very low due to the low amount of base material transport. The measured deviations in filter profile were mainly caused by ripple formation and ripple displacement at the sand-filter interface. The mean profile (averaged over the width of the flume) remained unchanged over all tests $(+/-3 \mathrm{~mm})$. Only at local scale (stone diameter size) was erosion and ripple building noticeable up to $1 D_{n 50, f}$ (ca. $20 \mathrm{~mm}$ ). The maximum observed ripple height was approximately equal to the maximum erosion depth. The occurrence of areas of maximum erosion were not correlated to the occurrence of ripple troughs. 


\section{TEST RESULTS}

In Figures 5 and 6 the measured transport rates are depicted. The lines in the figures show the found trends.
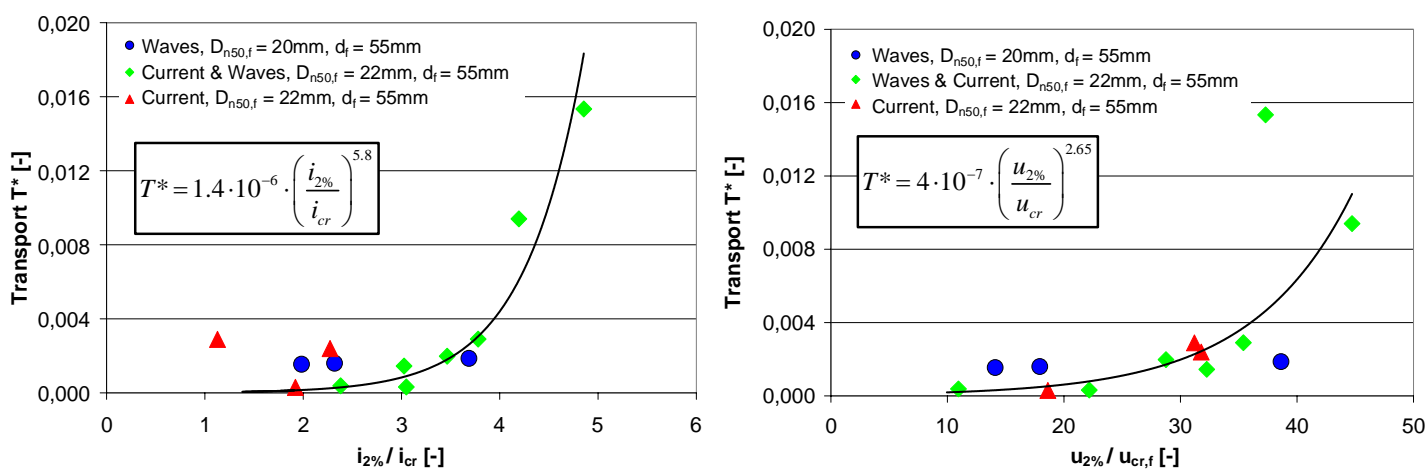

Figure 5. Transport vs. hydraulic gradient and Transport vs. velocity (current, current \& wave loading).
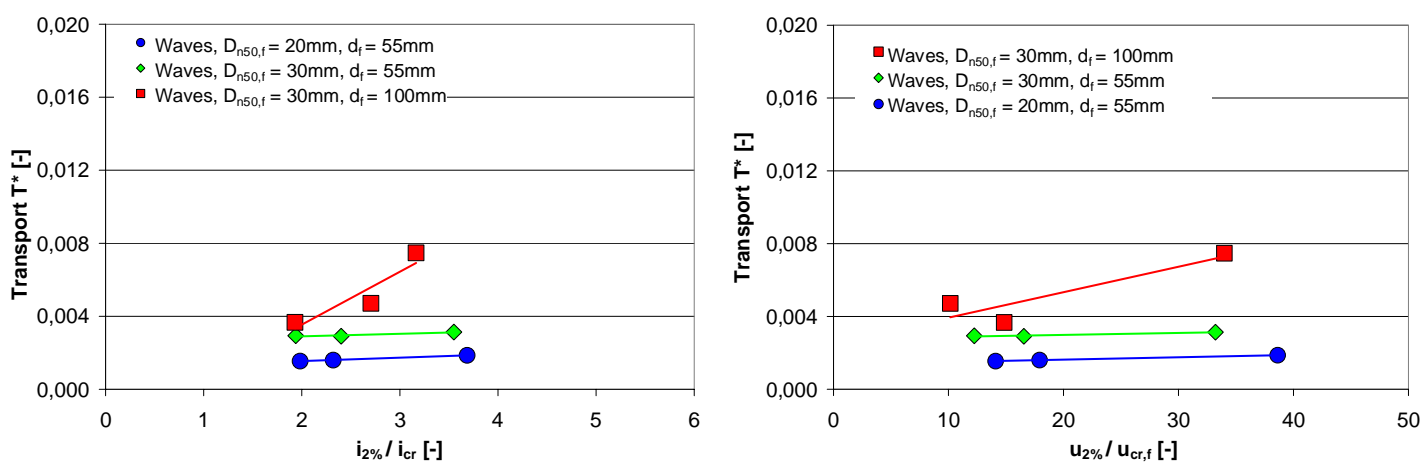

Figure 6. Transport vs. hydraulic gradient and Transport vs. velocity (wave loading, see Wolters et al, 2010).

Figure 5 shows that the measured transport rates $\left(T^{*}\right)$ are strongly correlated to the measured hydraulic gradients $i_{2 \%} / i_{c r}$ and velocities $u_{2 \%} / u_{c r}$, as already proposed by Klein Breteler et al (1992). In contrast to Klein Breteler et al (1992) the increase in transport with increasing $i_{2 \%} / i_{c r}$ appears to be much stronger (exponent of 5.8 instead of 1.25).

Please note that the filter velocities $u_{f}$ inside the filter were not actually measured in this study ( $u_{2 \%}$ is based on the velocities measured $25 \mathrm{~mm}$ above the filter), whereas $i$ and $i_{c r}$ have been directly measured at the sand-filter interface. The data based on $i_{2 \%} / i_{c r}$ are therefore found to be somewhat more reliable.

A strong increase in transport was found for $i_{2 \%} / i_{c r}>3.7$ respectively $u_{2} \% / u_{c r}>35$. Below these values base material transport was found to be very low (negligible for typical storm durations). Please note also that these gradients $\left(i_{2 \%} / i_{c r}>3.7\right)$ could not be achieved for the case of wave loading alone (Figure 6).

Recent large scale measurements indicate that under prototype (storm) conditions hydraulic gradients $i_{2 \%} / i_{c r}$ of up to 6 can be found (De Vroeg \& Muttray, 2009). However, similar gradients could not be generated in the here described small scale tests, indicating that significantly more base material transport can be expected at prototype scale.

Based on the tests on wave loading (Wolters et al, 2010), see Figure 6, it was expected that the base material transport would significantly increase for combined current \& wave conditions. The stirred up material under wave action, which remained around its rest position and was therefore not transported before, was expected to contribute largely to the measured transport rate. It was also assumed that the transport for current alone was lower than that for combined wave \& current action. A strong increase in transport was however not observed for the tested loading cases of current and wave \& current. The measured transport rates were still $\leq 0.33 \mathrm{~g} / \mathrm{m} / \mathrm{s}$ (which amounts to about a maximum of $7.5 \mathrm{~kg} / \mathrm{m}$ per 6 hours) for waves up to $H_{s}=0.15 \mathrm{~m}$ and currents up to $u_{2} \%=1.2 \mathrm{~m} / \mathrm{s}$. This indicates a strong 'protective' effect of the tested, relatively thin filter layer $\left(d_{f} / D_{\mathrm{n} 50, f}=1.8-3.3\right)$. 
Nevertheless, an increase of transport for combined wave \& current loading was found (compared to wave loading: factor of up to 7 , compared to current loading: factor of up to 5).

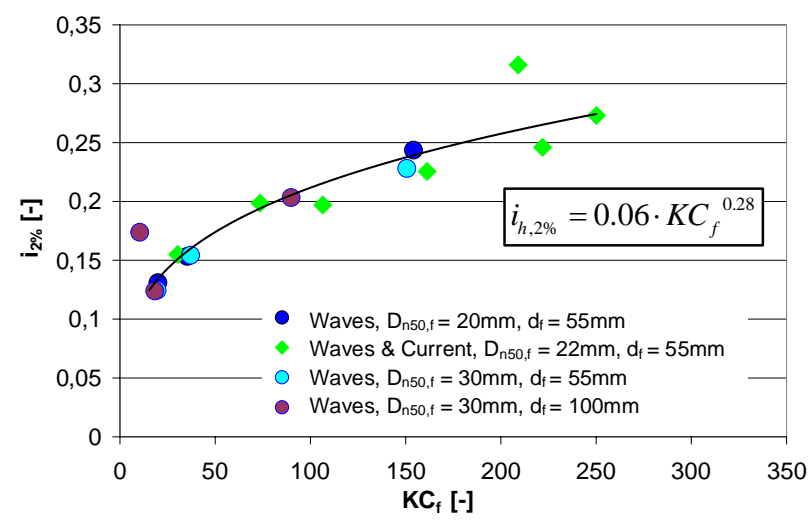

Figure 7. Transport vs. $K C_{f}$ number; $K C_{f}$ is based on the velocity measured $25 \mathrm{~mm}$ above the filter bed, $u_{2} \%$, and the filter thickness $d_{f}\left(K C_{f}=U_{2 \%} T_{m} /\left[n_{f} d_{f}\right]\right)$

Figure 7 shows that a strong relationship was found between $K C_{f}$ number and hydraulic gradient $i_{2 \%}$. The figure (in combination with Figure 5) indicates that base material transport can be described as a function of $i / i_{c r}\left(T=\mathrm{f}\left(i / i_{c r}\right)\right)$, where the hydraulic gradient $i$ is given as a function of $K C_{f}$. However, the indicated trends (relationships) need further verification, especially regarding the possible influence of variations in filter thickness. Filter thickness was expected to have an influence on the hydraulic gradient, although for the tested two filter thicknesses no influence could be found.

\section{Influence of filter}

In Test T13 (current alone) and Test T14 (current \& waves) the filter layer $\left(d_{f} / D_{\mathrm{n} 50, f}=2.5\right)$ was completely removed to acquire reference data on the material transport without filter. A strong effect on bed material transport was observed:

For current loading, the transport increased from $0.006 \mathrm{~g} / \mathrm{m} / \mathrm{s}$ to $12.3 \mathrm{~g} / \mathrm{m} / \mathrm{s}$ (factor 2050) and for combined wave \& current loading from $0.043 \mathrm{~g} / \mathrm{m} / \mathrm{s}$ to $33.6 \mathrm{~g} / \mathrm{m} / \mathrm{s}$ (factor 781 ), see Figure 8 (left). Because of the large quantities of sand transported, each test was stopped after 30 minutes.

Without the protection of the filter layer, the entire top layer of the sand bed came into motion when waves passed over it (whereas only localized particle motion was observed for the current-alone test T13). In contrast to the tests with filter, the bedforms of the sand changed also: much larger variances in size and form of ripples (ripples with steep rearside and symmetric ripples of half-circle form) were observed.
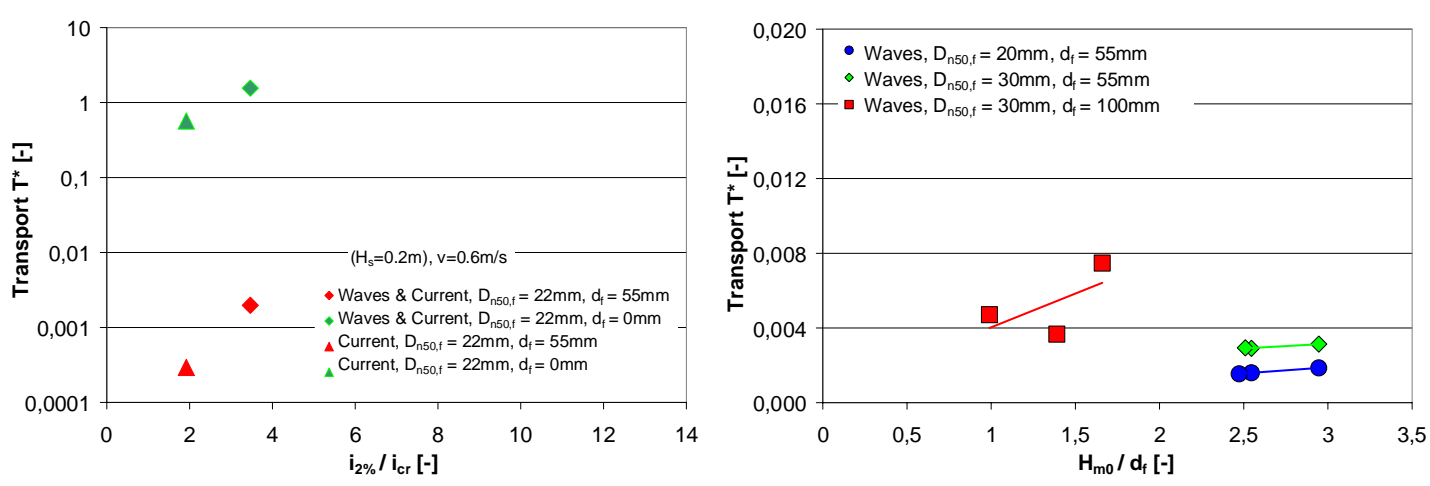

Figure 8. Influence of filter layer for the test case $H_{s}=0.2 \mathrm{~m}$ and $u_{m}=0.6 \mathrm{~m} / \mathrm{s}$.

Figure 8 (right) indicates that varying filter thickness affects the sand transport rates more strongly than varying filter material diameters (only investigated for wave loading case). As indicated before, the effect of filter thickness needs further research, since the present data is insufficient. Please note that the measured transport rates for the case of $d_{f}=0.1 \mathrm{~m}$ are larger than for a filter thickness of $d_{f}=0.055 \mathrm{~m}$. This finding appears counterintuitive and cannot be explained at present. 


\section{Comparison with macroscopic transport model of Klein Breteler et al (1992)}

If the results of the present investigation are compared with the (steady flow) model of Klein Breteler et al (1992), it becomes apparent that the predicted transport rates based on Equation 5 are much larger than measured in the present tests (by factor of $30-920$ ). On the other hand, the increase in transport with increasing $i / i_{c r}$ is significantly lower $\left(\left(i / i_{c r}\right)^{1.25}\right.$ compared to $\left(i / i_{c r}\right)^{5.8}$ in the present tests). This large deviation is found for all loading cases (current, wave, wave \& current). At present it is assumed that the main reason for the deviations is the varying model set-up: Klein Breteler et al (1992) used a closed 'filter box', which guaranteed a nearly constant filter velocity over the depth, while the present tests were conducted with a free water surface. Also note that Klein Breteler et al's (1992) study investigated current loading and included no waves.

\section{CONCLUSIONS}

The presented 2D physical model study focussed on geometrically open granular filters on a submerged, horizontal sand bed. Tests were conducted for filters under wave, current and combined wave \& current loading. The following conclusions were drawn:

- Bed material (sand) transport in a granular filter structure can be described as function of the hydraulic gradient $i_{2 \%} / i_{c r}$, independent of the loading condition (wave / current / wave \& current).

- The hydraulic gradient $i_{2 \%} / i_{c r}$ can be estimated using the modified Keulegan-Carpenter $\left(K C_{f}\right)$ number.

- $\quad$ For hydraulic gradients $i_{2 \%} / i_{c r}<3$, a thin protective granular filter layer $\left(d_{f}=2 D_{\mathrm{n} 50, f}-3 D_{\mathrm{n} 50, f}\right)$ on top of the sand bed was observed to reduce the sand transport rates so far that no significant bed erosion (damage) occurred.

- For conditions with a current alone and conditions with waves only, very low base material transport rates were recorded $(<0.06 \mathrm{~g} / \mathrm{m} / \mathrm{s}$ respectively $<0.16 \mathrm{~g} / \mathrm{m} / \mathrm{s})$. For conditions with a combination of waves and a current the transport increased somewhat (up to $0.33 \mathrm{~g} / \mathrm{m} / \mathrm{s}$ ) for generated waves up to $H_{s}=0.2 \mathrm{~m}$ and depth-averaged current velocities of $u_{m}=1 \mathrm{~m} / \mathrm{s}$.

- A strong increase in transport was found for hydraulic gradients $i_{2 \%} / i_{c r}>3.7$ (storm conditions). For these conditions significant erosion of the base material is expected in prototype. Recent large scale measurements indicate that under prototype (storm) conditions hydraulic gradients $i_{2 \%} / i_{c r}$ of up to 6 can be found (De Vroeg \& Muttray, 2009).

- A dominant effect of filter thickness on base material transport was found. Due to the limited amount of performed tests, this effect needs further study. The same is valid for the influence of filter gradation and bed slope, which were not investigated in this study.

- An equilibrium situation (after initial scouring) has so far not been found in any of the conducted studies.

- Verification of the results at large model scale and under oblique waves is recommended.

\section{REFERENCES}

Bakker K.J., Verheij H.J., and de Groot M.B. 1994. Design relationship for filters in bed protection”. J. Hydraulic Eng., 120(9), 1082-1088.

CUR report 161. 1993. Filters in hydraulic engineering, Gouda (in Dutch).

CUR report 233. 2010. Interface stability of granular filter structures, Theoretical design methods for currents, CURNET, Gouda.

Den Adel H. 1992. Transport model for filters, Deel 1-3, report C0-325970/6, Delft Hydraulics (in Dutch).

De Graauw, A., Van der Meulen, T., Van der Does de Bye, M. 1983. Design criteria for granular filters, Publication 287, Delft Hydraulics.

Dixen, F.H., Sumer, B.M. and Fredsoe, J. 2008. Suction removal of sediment from between armor blocks. II: waves, J. of Hydraul. Eng., Vol 134, no 10, October 2008, ASCE.

Klein Breteler M. 1989. Sand transport in granular filters, horizontal steady current, report H869, Delft Hydraulics (in Dutch).

Klein Breteler M., Den Adel H., Koenders M.A. 1992. Slope protections of set stone (revetment), Design rules for the filter layer, Report M1795/H195, XXI, Delft Hydraulics \& Geo Delft (in Dutch).

Ockeloen, W.J. 2007. Open filters in breakwaters with a sand core, M.Sc. thesis, TU Delft. 
Sumer, B. M., Cokgor, S., and Fredsøe, J. 2001. Suction removal of sediment from between armor blocks, J. Hydraul. Eng., 127(4), 293-306.

Uelman, E.F. 2006. Geometrically open filters in breakwaters, M.Sc. thesis, TU Delft.

Van Gent, M.R.A. 1995. Wave interaction with permeable coastal structures, Ph.D.-dissertation, Delft University of Technology, ISBN 90-407-1182-8, Delft University Press, Delft.

Vroeg de J.H. and Muttray M. 2009. Stability of sand under an open filter, Desk study, Deltares, internal communication (in Dutch).

Wolters G., D. Rudolph, B. Hofland, H. Verheij. 2010. On the behaviour of Open Filters under wave loading, Proc. $5^{\text {th }}$ International Conference on Scour and Erosion (San Francisco), Geotechnical Special Publication 210, ASCE. 